\title{
ЭЛЕКТРОННО-ЛУЧЕВЫЕ \\ ПРОЦЕССЫ
}

УДК 669.187 .826

\section{ЭЛЕКТРОННО-ЛУЧЕВАЯ ПЛАВКА СЛИТКОВ ЖАРОПРОЧНЫХ СПЛАВОВ НА ОСНОВЕ НИКЕЛЯ}

\author{
С.В. Ахонин, В.А. Березос, А.Н. Пикулин, А.Ю. Северин, А.Г. Ерохин \\ Институт электросварки им. Е.О. Патона НАН Украины. \\ 03680, г. Киев-150, ул. Боженко, 11. E-mail: office@paton.kiev.ua
}

\begin{abstract}
С целью изучения степени очистки сложнолегированных жаропрочных сплавов на основе никеля и отработки технологии их производства в ИЭС им. Е.О. Патона НАН Украины проведены работы по выплавке партии слитков марок ЭП708, ЭИ648 и ЭИ698. Слитки получали по технологии электронно-лучевой плавки с промежуточной емкостью и порционной подачей жидкого металла в водоохлаждаемый кристаллизатор. Показана возможность применения электронно-лучевой плавки вместо вакуумно-дуговой для переплава заготовок открытой индукционной плавки. Проведены работы по получению слитков из жаропрочных сплавов на основе никеля ЭП708 и ЭИ698 путем вовлечения в шихтовую заготовку 100 \% оборотного сырья. Показана перспективность применения технологии ЭЛП для переработки лома жаропрочных сплавов на основе никеля в высококачественные слитки. Отработана технология получения высококачественных слитков-слябов жаропрочных сплавов на основе никеля способом электронно-лучевой плавки. Показано, что электронно-лучевой переплав является эффективным способом получения качественных слитков жаропрочных сплавов на основе никеля, которые по химическому составу полностью соответствуют требованиям стандартов. При этом металл слитков характеризуется пониженным содержанием газов и неметаллических включений. Библиогр. 10, табл. 5, ил. 6.
\end{abstract}

Кл п че в ы е сл ов а : жаропрочная сталь; сплав на основе никеля; шихтовая заготовка; слиток; электронно-лучевая плавка; промежуточная емкость; рафинирование; легирующие; примеси; качество металла

Развитие новых отраслей техники выдвигает все новые требования к чистоте и свойствам сплавов различного назначения, поэтому повышение качества конструкционных материалов является неотъемлемым условием прогресса. За последнее время произошли большие изменения в металлургии выплавки жаропрочных и окалиностойких сплавов. Получение их в открытых индукционных (ИП) и дуговых сталеплавильных печах (ДСП) постепенно заменяется выплавкой в вакуумных печах различного типа [1]. Применяются следующие способы плавок: вакуумно-индукционная (ВИП); вакуумно-дуговая (ВДП) с расходуемым электродом; дуплекс-процесс (выплавка в индукционных печах и переплав в вакуумно-дуговых); электронно-лучевая (ЭЛП); плазменно-дуговая (ПДП) [2]. В настоящее время наиболее традиционной технологией для выплавки жаропрочных, нержавеющих, магнитных и жаростойких сплавов является ВИП с последующим ВДП [3].

Свойства конструкционных материалов в значительной степени зависят от снижения содержания в них газов, вредных примесей и неметаллических включений, а также полученной плотной бездефектной структуры слитка [4]. Именно су- ществующие способы специальной электрометаллургии позволяют повысить механические и физико-химические свойства металлов и сплавов [3, 5]. Однако эти способы не всегда могут соответствовать необходимым требованиям, предъявляемым к качеству сплавов такого класса.

В настоящее время прогрессивным способом качественной металлургии является электронно-лучевая плавка [6]. Она нашла применение в промышленности для получения металлов с минимальным содержанием газов, летучих примесей и неметаллических включений [7]. Основные характерные черты: наличие высокого вакуума в процессе плавки; большая контактная поверхность металл-вакуум за счет капельного переноса с поверхности переплавляемой заготовки в расплав жидкого металла, создает исключительно благоприятные условия для протекания диффузионных процессов вакуумного рафинирования; исключена возможность загрязнения металла в зоне плавки материалами огнеупорного тигля изза применения медных кристаллизаторов; регулировка в широких пределах технологических параметров плавки - удельной мощности, времени выдержки металла в расплавленном состоянии, 


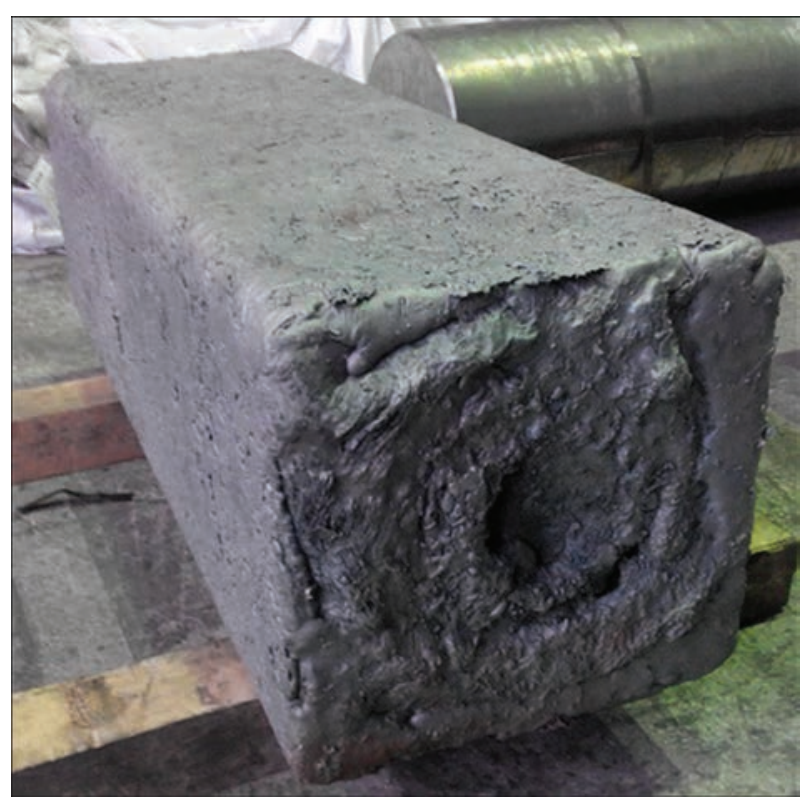

Рис. 1. Шихтовая заготовка для выплавки жаропрочного сплава на основе никеля ЭИ648

температуры, что позволяет влиять на процессы рафинирования; получение структуры выплавляемого слитка без каких-либо металлургических дефектов за счет мелкой жидкой ванны в кристаллизаторе.

С целью изучения степени очистки сложнолегированных жаропрочных сплавов на основе никеля и отработки технологии их производства в ИЭС им. Е.О. Патона НАН Украины проведены работы по выплавке партии слитков марок ЭП708, ЭИ648 и ЭИ698. Слитки получали по технологии ЭЛП с промежуточной емкостью и порционной подачей жидкого металла в водоохлаждаемый кристаллизатор.

Шихтовая заготовка для выплавки слитка сплава марок ЭИ648 представляла собой слиток первичного индукционного переплава (рис. 1).

На основе ранее проведенных в ИЭС им. Е.О. Патона НАН Украины фундаментальных исследований процессов испарения компонентов сплавов из расплава в вакууме проводили расчеты прогнозируемого химического состава выплавляемого слитка, по результатам которых осуществляли корректировку составляющих шихтовой заготовки $[8,9]$. Легирующие компоненты с высокой упругостью пара $(\mathrm{Al}, \mathrm{Cr})$ добавляли с учетом компенсации потерь на испарение.

После формирования расходуемой заготовки установку герметизировали и вакуумировали. В процессе плавки исходную шихту непрерывно с заданной скоростью подавали в зону плавки над промежуточной емкостью, где под действием электронно-лучевого нагрева происходило ее сплавление. После наполнения промежуточной емкости жидкий металл сливали в водоохлажда-

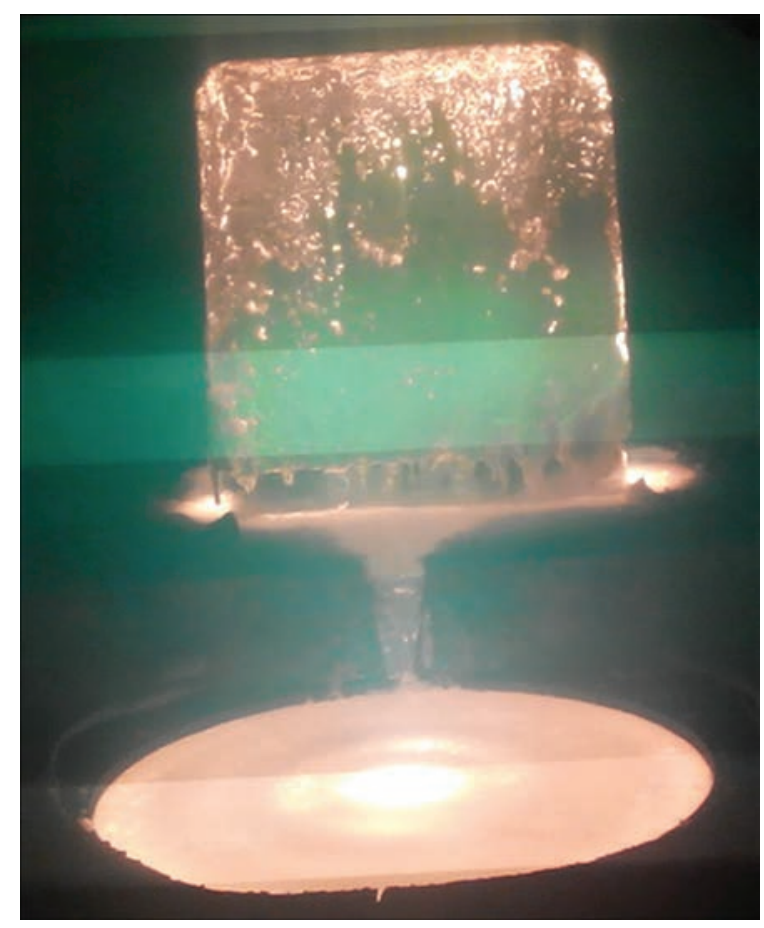

Рис. 2. Процесс ЭЛП жаропрочного сплава на основе никеля ЭИ648

емый медный кристаллизатор. По мере наплавки слиток опускали вниз механизмом вытягивания по полунепрерывному режиму. После повышения уровня жидкого металла в кристаллизаторе на $10 \ldots 15$ мм слиток опускали с линейной скоростью (2...3) $\cdot 10^{-4} \mathrm{~m} / \mathrm{c}$ до тех пор, пока ванна не достигнет прежнего уровня. Вытягивание слитка производили после каждого слива порции жидкого металла в кристаллизатор.

Процесс плавки протекал стабильно, однако наблюдалось выделение значительного количества шлака, который задерживался в промежуточной емкости за счет теплового барьера в зоне плавки и в жидкий расплав в кристаллизаторе не попадал (рис. 2).

С целью улучшения процессов рафинирования от вредных примесей и включений при выплавке слитков жаропрочных сплавов на основе никеля было увеличено время выдержки жидкого металла в промежуточной емкости и кристаллизаторе за счет снижения производительности плавки от 280 до 220 кг/ч.

В стационарном режиме наплавляли слиток необходимой длины. После этого в головной части слитка выводилась усадочная раковина. Слитки остывали в вакууме вместе с камерой, после чего установку развакуумировали и слиток выгружали цеховым краном. Получены слитки жаропрочного сплава на основе никеля ЭИ648 (рис. 3, 4).

С целью оценки качества металла полученного слитка проводили исследования химического 


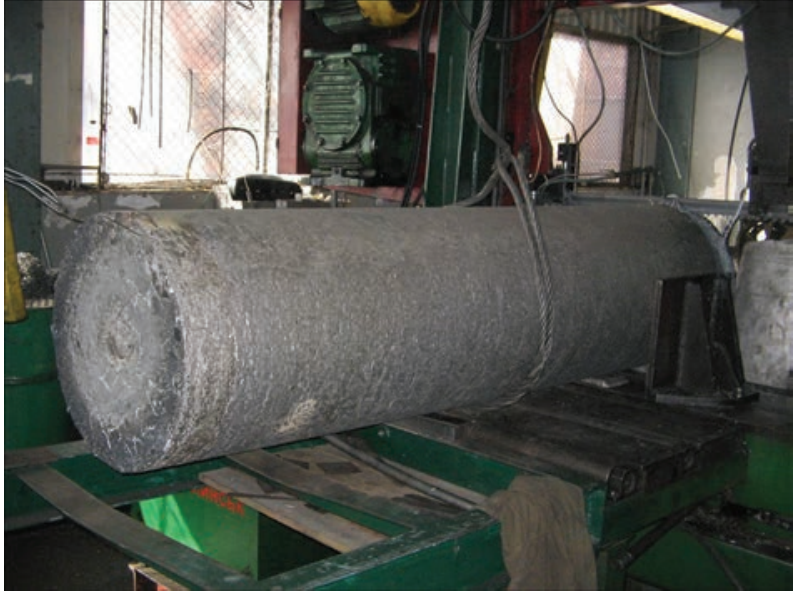

Рис. 3. Слиток диаметром 500 мм жаропрочного сплава на основе никеля ЭИ648

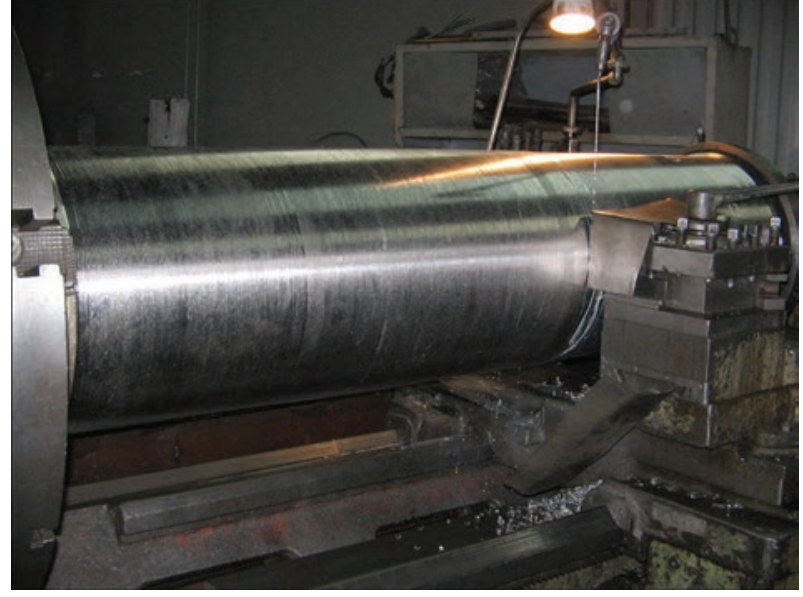

Рис. 4. Механически обработанный слиток диаметром 500 мм жаропрочного сплава на основе никеля ЭИ648

Т а б л и ц а $\mathbf{1}$. Химический состав элементов и примесей распределенных по длине слитка диаметром 400 мм сплава
ЭИ648, мас. \%
\begin{tabular}{|c|c|c|c|c|c|c|c|c|c|} 
Образец & $\mathbf{T i}$ & $\mathbf{C r}$ & $\mathbf{S i}$ & $\mathbf{F e}$ & $\mathbf{N b}$ & $\mathbf{M o}$ & $\mathbf{W}$ & $\mathbf{A l}$ & $\mathbf{N i}$ \\
\hline Шихта & 1,34 & 34,4 & 0,03 & 0,87 & 0,89 & 2,75 & 4,83 & 1,5 & Основа \\
ЭЛП & 0,98 & 31,8 & 0,01 & 0,60 & 0,90 & 2,8 & 4,8 & 0,9 & $-\gg-$ \\
ТУ & $0,5 \ldots 1,1$ & $32 \ldots 35$ & $<0,4$ & $<4,0$ & $0,5 \ldots 1,1$ & $2,3 \ldots 3,3$ & $4,5 \ldots 5,3$ & $0,5 \ldots 1,1$ & $-\gg-$ \\
\hline
\end{tabular}

состава образцов, отобранных по длине слитка в верхней, средней и нижней частях. Результаты анализа химического состава металла сплава ЭИ648 показали, что распределение легирующих элементов по длине равномерное и соответствует марочному (табл. 1).

Слитки жаропрочного сплава на основе никеля ЭИ648 электронно-лучевой плавки исследовали на содержание газов. Результаты газового анализа слитков приведены в табл. 2.

Из таблицы видно, что содержание кислорода в металле после ЭЛП снижается на 75, а азота на 60 \%.

В настоящее время актуально вовлечение оборотного сырья в процесс плавки слитков жаропрочных сплавов на основе никеля. Однако, при использовании обрези в процессе следующей плавки в составе металла накапливаются вредные примеси и, как результат, снижается уровень механических свойств в готовых изделиях [10]. Имея широкие возможности электронно-лучевая плавка позволяет решить ряд важных задач при получении высококачественных слитков жаропрочных сплавов из повторно используемого сырья.

Т а бл и ц а 2. Содержание газов в сплаве ЭИ648 до и после ЭЛП, \%

\begin{tabular}{|c|c|c|}
\hline Металл & [О] & [N] \\
\hline Исходный & 0,004 & 0,04 \\
После ЭЛП & 0,001 & 0,015 \\
\hline
\end{tabular}

Проведены работы по получению слитков из жаропрочных сплавов на основе никеля ЭП708 и ЭИ698 путем вовлечения в шихтовую заготовку $100 \%$ оборотного сырья (рис. 5). Отработана тех-

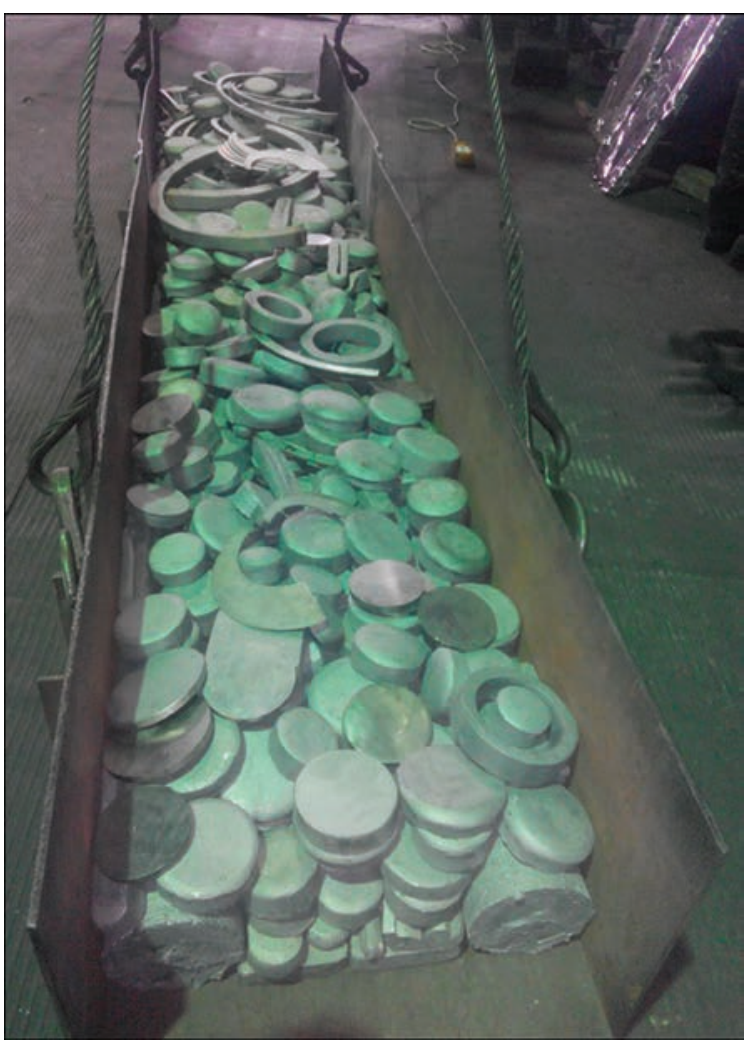

Рис. 5. Шихтовая заготовка для выплавки слитка жаропрочного сплава ЭП708 


\begin{tabular}{|c|c|c|c|c|c|c|c|c|c|c|c|}
\hline Образец & $\mathbf{S}$ & $\mathbf{S i}$ & Mn & $\mathrm{Fe}$ & $\mathrm{Cr}$ & Ti & Al & Mo & $\mathbf{W}$ & $\mathrm{Nb}$ & $\mathrm{Ni}$ \\
\hline \multicolumn{12}{|c|}{ Сплав ЭП 708} \\
\hline Шихта & 0,014 & 0,46 & 0,60 & 3,3 & 18,0 & 1,8 & 2,2 & 4,9 & 5,7 & - & основа \\
\hline ЭЛП & 0,005 & 0,45 & 0,20 & 2,9 & 19,0 & 1,6 & 2,0 & 4,8 & 5,8 & - & $-\gg-$ \\
\hline ТУ & $<0,015$ & $<0,6$ & $<0,3$ & $<4,0$ & $17,5 \ldots 20,0$ & $1,0 \ldots 1,4$ & $1,9 \ldots 2,3$ & $4,0 \ldots 6,0$ & $5,5 \ldots 7,5$ & - & $-\gg-$ \\
\hline \multicolumn{12}{|c|}{ Сплав ЭИ698 } \\
\hline Шихта & 0,008 & 0,51 & 0,48 & 2,0 & 14,0 & 2,8 & 1,6 & 2,8 & - & 2,0 & основа \\
\hline ЭЛП & 0,004 & 0,5 & 0,21 & 1,6 & 15,5 & 2,65 & 1,45 & 2,9 & - & 2,0 & $-\gg-$ \\
\hline ТУ & $<0,007$ & $<0,6$ & $<0,4$ & $<2,0$ & $13 \ldots 16$ & $2,35 \ldots 2,75$ & $1,3 \ldots 1,7$ & $2,3 \ldots 3,2$ & - & $1,8 \ldots 2,2$ & $-\gg-$ \\
\hline
\end{tabular}

нология получения слитков прямоугольного сечения из жаропрочного сплава ЭП708 (рис. 6).

Шихтовую заготовку для выплавки слитков формировали в нерасходуемый короб. Заготовки представляли собой плотно уложенный лом указанных марок сплавов (рис. 5).

Результаты анализа химического состава металла полученных слитков-слябов сплавов ЭП708 и ЭИ698 до и после ЭЛП приведены в табл. 3.

Сравнительный анализ сплавов показал, что при ЭЛП рафинирование марганцем и серой увеличивается в 2-3 раза. Несколько снижается содержание железа. Содержание кремния и тугоплавких элементов (молибдена, ниобия, вольфрама) практически не изменяется. Электронно-лучевой переплав лома жаропрочных сплавов ЭП708 и ЭИ698 сопровождается нежелательным эффектом



Рис. 6. Внешний вид слитка-сляба сплава ЭП708 размерами $155 \times 540 \times 2500 \mathrm{MM}$

\begin{tabular}{|c|c|c|}
\hline Способ плавки & [O] & {$[\mathbf{N}]$} \\
\hline ДСП & 0,0035 & 0,039 \\
\hline ВИП & 0,0022 & 0,035 \\
\hline ВДП & 0,0017 & 0,026 \\
\hline ЭЛП & 0,0015 & 0,012 \\
\hline
\end{tabular}

удаления таких легирующих элементов как хром и алюминий. Их потери можно компенсировать повышенным содержанием их в исходной шихтовой заготовке, либо достаточно переплавлять данные марки сплавов с содержанием хрома и алюминия на верхнем пределе марочного состава.

В процессе работы проведен сравнительный анализ содержания газов в сплаве ЭИ698 после ДСП, ВИП, ВДП и ЭЛП (табл. 4).

Из анализа данных таблицы следует, что ЭЛП жаропрочных сплавов на основе никеля обеспечивает дальнейшее повышение их чистоты, а именно снижение содержания газов по отношению к другим видам переплавов: кислорода в 1,5-2,0, азота в 2-3 раза.

Оценку загрязненности жаропрочного сплава ЭИ698 неметаллическими включениями проводили по ГОСТ 1778-70 на образцах, вырезанных из слитка. Размеры неметаллических включений в слитке ЭЛП значительно меньше, чем в исходном металле. Максимальный размер включений в сплаве в исходном состоянии составляет $16 \ldots 18$, после ЭЛП $-8 \ldots 10$ мкм.

\begin{tabular}{|c|c|c|}
\hline \multirow{2}{*}{$\begin{array}{l}\text { T а бл и ц а } \\
\text { скими включениями жаропрочного сплава ЭИ698 }\end{array}$} \\
\hline \multirow{2}{*}{ Образец } & \multicolumn{2}{|c|}{ Оченена загрязненности, балл } \\
\cline { 2 - 3 } & Максимальный & Средний \\
\hline \multirow{2}{*}{$\begin{array}{l}\text { Исходный } \\
\text { После ЭЛП }\end{array}$} & 3 & 2 \\
\hline
\end{tabular}


Оценка загрязненности неметаллическими включениями представлена средним баллом, как среднеарифметическое максимальных оценок отдельных образцов (табл. 5).

Таким образом, проведенные работы показали, что ЭЛП является эффективным способом получения качественных слитков жаропрочных сплавов на основе никеля, которые по химическому составу полностью соответствуют требованиям стандартов. При этом металл слитков характеризуется пониженным содержанием газов и неметаллических включений.

\section{Выводы}

1. Показана возможность применения ЭЛП вместо ВДП для переплава заготовок открытой индукционной плавки.

2. Проведенные исследования показали перспективность применения технологии ЭЛП для переработки лома жаропрочных сплавов на основе никеля в высококачественные слитки.

3. Отработана технология получения высококачественных слитков-слябов жаропрочных сплавов на основе никеля способом ЭЛП.

4. Установлено, что способ ЭЛП жаропрочных сплавов на основе никеля позволяет получить вы- сококачественные слитки с низким содержанием газов и неметаллических включений.

1. Иванов И.Н., Вихреева Р.К. Экономика вакуумной металлургии. - М.: Металлургия, 1989. - 121 с.

2. Лейканд М.С. Вакуумные электрические печи. - М.: Машиностроение, 1977. - 52 с.

3. Самарин А.М. Вакуумная металлургия. - М.: Гос. науч.-техн. изд-во лит. по черн. и цвет. металлургии, 1962. $-512 \mathrm{c}$.

4. Электронно-лучевая плавка / Б.Е. Патон., Н.П. Тригуб, Д.А. Козлитин и др. — Киев: Наук. думка, 1997. — 265 с.

5. Рафинирующие переплавы стали и сплавов в вакууме / В.А. Бояришников, А.Г. Шалимов, А.И. Щербаков и др. - М.: Металлургия, 1979. - 304 с.

6. Патон Б.Е., Тригуб Н.П., Ахонин С.В. Электронно-лучевая плавка. - Киев: Наук. думка, 2008. - 311 с.

7. Мовчан Б.А., Тихоновский А.Л., Курапов Ю.А. Электронно-лучевая плавка и рафинирование металлов и сплавов. - Киев: Наук. думка, 1973. - 240 с.

8. Тихоновский А.Л., Ахонин С.В. Расчетный способ обеспечения заданного состава сплавов при ЭЛП. Физико-химические основы металлургических процессов. Ч. 2. - М.: Черметинформация, 1991. - С. 16-18.

9. Тригуб Н.П., Ахонин С.В. Оптимизация выплавки слитков сталей и сплавов в электронно-лучевой установке с промежуточной емкостью // Пробл. спец. электрометаллургии. - 1996. - № 2. - С. 12-17.

10. Ощчепков Б.В., Жильц̧ова Т.А. Совершенствование технологии выплавки жаропрочных сплавов на никелевой основе в ОДП с использованием легированных отходов // Вестник ЮУрГУ. — 2012. — № 15. - С. 100-101.

To study the degree of purification of complexly-alloyed heat-resistant alloys on nickel base and to optimize the technology of their production, the works were carried at the E.O. Paton Electric Welding Institute of The NAS of Ukraine for melting a batch of ingots of EP708, EI648 and EI698 grades. The ingots were produced by the technology of electron beam melting with a cold hearth and portion feeding of molten metal into a water-cooled mould. The possibility of application of electron beam melting instead of vacuum-arc one for remelting of billets of open induction melting is shown. The works were carried out for producing ingots of heat-resistant nickel-based alloys EP708 and EI698 by adding of $100 \%$ reverse raw material into the charge billet. The challenge of application of EBM technology is shown for processing of scrap of heat-resistant alloys on nickel base into the high-quality ingots. The technology has been optimized for producing the high-quality ingots-slabs of nickel-based heat-resistant alloys using the method of electron beam melting. It is shown that the electron beam remelting is the effective method of producing the quality nickel-based heat-resistant alloys which by chemical composition meet completely the requirements of standards. Moreover, the ingot metal is characterized by a lower content of gases and non-metallic inclusions. Ref. 10. Tables 5, Figures 6.

Key words: heat-resistant steel; alloy on nickel base; charge billet; ingot; electron beam melting; cold hearth; refining; alloying impurities; metal quality

Поступила 26.11.2015

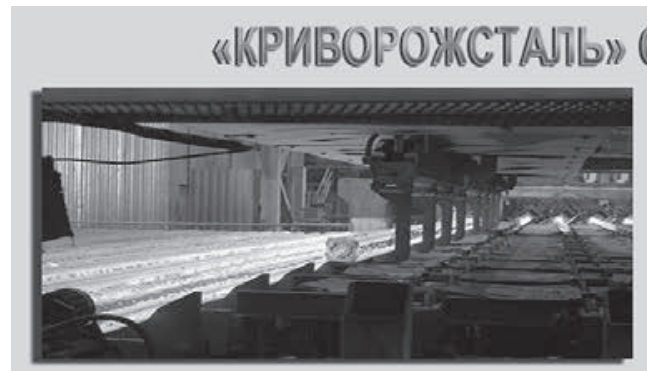

http://www.azovpromstal.com/news
В ПАО «АрселорМиттал Кривой Рог» прошли сертификационные аудиты на соответствие израильскому и польскому стандартам SI 4466 и PN-H-93220:2006.

Результаты испытаний подтвердили соответствие продукции установленным требованиям.

«В ходе аудита не выявлено несоответствий, препятствующих успешной сертификации», - сообщила директор департамента по качеству Елена Кузьменко.

Как рассказали в пресс-службе АрселорМиттал, в ходе визитов аудиторы посетили ряд производственных подразделений, таких как конвертерный цех, блюминг, сортопрокатные цехи №1 и 2.

Специалисты Института Стандартизации Израиля и компании ZETOM приняли участие в испытаниях арматурного проката по требованиям национальных стандартов Израиля и Польши. 